\title{
Effect of thematic map misclassification on landscape multi-metric assessment
}

\author{
William J. Kleindl • Scott L. Powell • F. Richard Hauer
}

Received: 1 January 2015 / Accepted: 16 April 2015 /Published online: 5 May 2015

(C) The Author(s) 2015. This article is published with open access at Springerlink.com

\begin{abstract}
Advancements in remote sensing and computational tools have increased our awareness of largescale environmental problems, thereby creating a need for monitoring, assessment, and management at these scales. Over the last decade, several watershed and regional multi-metric indices have been developed to assist decision-makers with planning actions of these scales. However, these tools use remote-sensing products that are subject to land-cover misclassification, and these errors are rarely incorporated in the assessment results. Here, we examined the sensitivity of a landscape-scale multi-metric index (MMI) to error from thematic land-cover misclassification and the implications of this uncertainty for resource management decisions. Through a case study, we used a simplified floodplain MMI assessment tool, whose metrics were derived from Landsat thematic maps, to initially provide results that were naive to thematic misclassification error. Using a Monte Carlo simulation model, we then incorporated map misclassification error into our MMI, resulting in four important conclusions: (1) each metric had a different sensitivity to error; (2) within each metric, the bias between the error-naive metric scores and simulated scores that incorporate potential error varied
\end{abstract}

\section{W. J. Kleindl $(\bowtie) \cdot$ F. R. Hauer}

Flathead Lake Biological Station and Montana Institute on Ecosystems, University of Montana, Missoula, MT 59812, USA

e-mail: b.kleindl@naiadllc.com

\section{S. L. Powell}

Department of Land Resources and Environmental Sciences, Montana State University, Bozeman, MT 59717, USA in magnitude and direction depending on the underlying land cover at each assessment site; (3) collectively, when the metrics were combined into a multi-metric index, the effects were attenuated; and (4) the index bias indicated that our naive assessment model may overestimate floodplain condition of sites with limited human impacts and, to a lesser extent, either over- or underestimated floodplain condition of sites with mixed land use.

Keywords Landscape pattern · Land-use intensity . Thematic classification accuracy - Landscape metrics . Bias $\cdot$ Remote sensing

\section{Introduction}

Advances in ecological assessment tools designed to assist in the management of aquatic systems at broad spatial scales have paralleled increased access to remote-sensing products and advances in geographic information processing. Remote-sensing products, such as thematic maps from Landsat or orthorectified imagery, provide the necessary baseline data to link alterations in landscape structure to perturbations in ecosystem functions at these large scales. These remotesensing data have known errors that should be, and generally are, clearly articulated in the metadata or associated accuracy reports. However, efforts to incorporate these errors into ancillary products, such as assessment tools, remain limited (Shao and Wu 2008). Ignoring the implications of these known errors on the results of assessment models potentially affects the level 
of confidence that resource managers have in the information the tools provide, and ultimately determines the extent to which the tool is used.

Indicator-based ecological assessment models have been developed to provide decision and policy makers with the needed ecological information for determining resource management decisions, communicating those decisions to the public, and developing rules to protect resources (Turnhout et al. 2007; Dramstad 2009). In reviews of contemporary aquatic assessment models, the multi-metric index (MMI) was the predominant indicator-based approach (Diaz et al. 2004; Fennessy et al. 2004; Böhringer and Jochem 2007). MMI tools developed for assessments at watershed scales (Brooks et al. 2004; Tiner 2004; Weller et al. 2007; Meixler and Bain 2010), regional scales (e.g., Reiss and Brown 2007; Collins et al. 2008), or compiled to provide national scale assessments (USEPA 2013) commonly use remotely sensed data and imagery to develop scaleappropriate metrics (Fennessy et al. 2007). While cartographic data generally follow standardized reporting guidelines that articulate known uncertainties inherent in the product (Foody 2002), incorporating these known uncertainties into MMI tools is rare (Fore et al. 1994; Whigham et al. 1999; Stein et al. 2009) and tends to be absent in the assessment implementation and reporting phase (e.g., Smith et al. 1995; Hauer et al. 2002; Klimas et al. 2004; Collins et al. 2008).

Ideally, a well-constructed ecological MMI model is designed to facilitate resource decisions by providing straightforward analyses of ecological data to enable translation to management applications (Barbour et al. 1999). However, addressing the implications of uncertainty in these tools can be complex. The challenge is to provide a pathway to incorporate known uncertainties from multiple scale-appropriate data sources into an assessment tool used by planners, policy makers, lawyers, and scientists. In this paper, we address two questions to meet this challenge: How sensitive is a landscape-scale multi-metric index to error from input data (specifically thematic land-cover misclassification)? What are the implications of this uncertainty for resource management decisions?

\section{Methods}

To answer these questions, we developed a multi-metric index that uses thematic Landsat data to provide an assessment of floodplain conditions along $250 \mathrm{~km}$ of the Flathead River in northwestern Montana, USA. Typical of most multi-metric indices, our initial assessment did not account for misclassification errors within the thematic map and produced metric and index scores that were considered naive. We then provided an error simulation model to incorporate known map classification error into our multi-metric assessment tool by developing multiple potential map realizations based on classification probabilities and potential spatial correlations. We applied our MMI to each realization to bind the potential stochasticity of the classification error (noise) into a distribution of potential assessment scores. We then compared this distribution to the naive score to determine potential bias and the implications of that bias on management decisions.

Study area and site selection

Our assessment model was centered on the Flathead River system above Flathead Lake within northwestern Montana, USA and included portions of the North Fork, Middle Fork, and main stem of the Flathead River (Fig. 1). The study area consisted of land use and land cover (LULC) typical in floodplains of larger rivers in the Northern and Canadian Rocky Mountains (Fig. 2). The North Fork of the Flathead River has its headwaters in southeastern British Columbia, Canada and enters the study area as it crosses the U.S. border. Within the study area, the river flows $93 \mathrm{~km}$ south-by-southeast along the northwest boundary of Glacier National Park (GNP) through a broad U-shaped valley with expansive lowgradient montane alluvial floodplains that are predominantly covered with forest and grasslands (simply called "unmanaged lands" here) and occasional pasture, as well as urban and exurban development (called "managed lands" here). The Middle Fork has its headwaters in the Bob Marshall Wilderness Area and enters the study area as it emerges from the wilderness complex and meets the southwest GNP boundary. Within the study area, the Middle Fork flows $70 \mathrm{~km}$ through a series of confined and unconfined reaches within a narrow valley that also contains U.S. Highway 2, the Burlington Northern Santa Fe Railroad transportation corridor, and the small town of West Glacier, MT at the southwestern tip of GNP. The main Flathead River channel begins at the North and Middle Fork confluence and flows about $86 \mathrm{~km}$ southerly leaving the study area as it enters the $480 \mathrm{~km}^{2}$ Flathead Lake. Along the way, 
Fig. 1 Location of study area and the 19 floodplain assessment sites. N-1 through N-9 are on the North Fork of the Flathead, M-1 through M-3 are on the Middle Fork, and F-1 through F-7 are sites on the Flathead River main stem

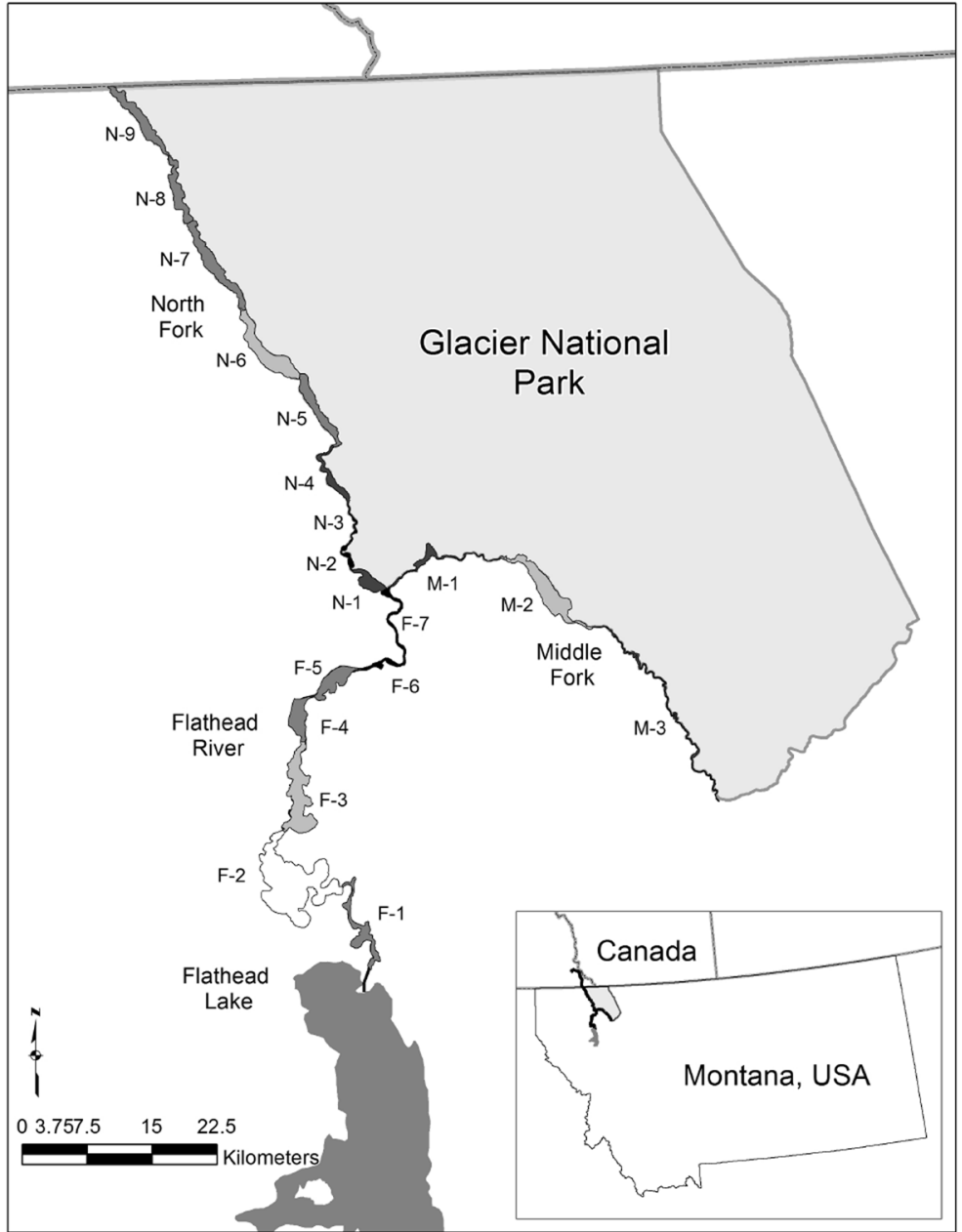

this sixth-order river leaves the confined forested slopes and enters a broad piedmont valley floodplain consisting of agricultural, urban, and exurban development interspersed with floodplain forest.

Nineteen assessment areas were selected based on continuous floodplain reaches separated by geomorphic constrictions on the river valley (Fig. 1): nine sites on the North Fork (numbered N-1 through N-9 from downstream to upstream), three sites on the Middle Fork (M-1 through M-3), and seven on the Flathead River main stem (F-1 through F-7). These sites consisted of both broad alluvial depositional areas typically associated with floodplain ecosystems and confined reaches with limited floodplain. Local biological diversity of river and floodplain systems is strongly influenced by surrounding land-use at several scales including local buffers (Morley and Karr 2002; Allan 2004; Pennington et al. 2010). To account for local land-use impacts adjacent to floodplain habitats, we established a $1-\mathrm{km}$ buffer to the entire floodplain area and delineated 19 buffer assessment sites perpendicular to the outer edge of each floodplain assessment site. The assessment sites and their buffers collectively have land use that ranges from forest to agriculture to urban, with human population densities ranging from 1 to 636 people per kilometer (Montana State Library 2011, Fig. 2).

The 19 assessment sites were digitized in ArcGIS 10.0 (ESRI 2011) with the assistance of 2005 background orthoimagery from the USDA National Agriculture Imagery Program (NAIP; USGS 2014). Digitalization was aided with a 30-m digital elevation map (USGS 2013), visual assistance from oblique views within Google Earth's 3-D models (Google Earth 2013), oblique imagery from aerial reconnaissance, and multiple site visits. Unless otherwise stated, all data collection, organization, and subsequent analyses were conducted in 


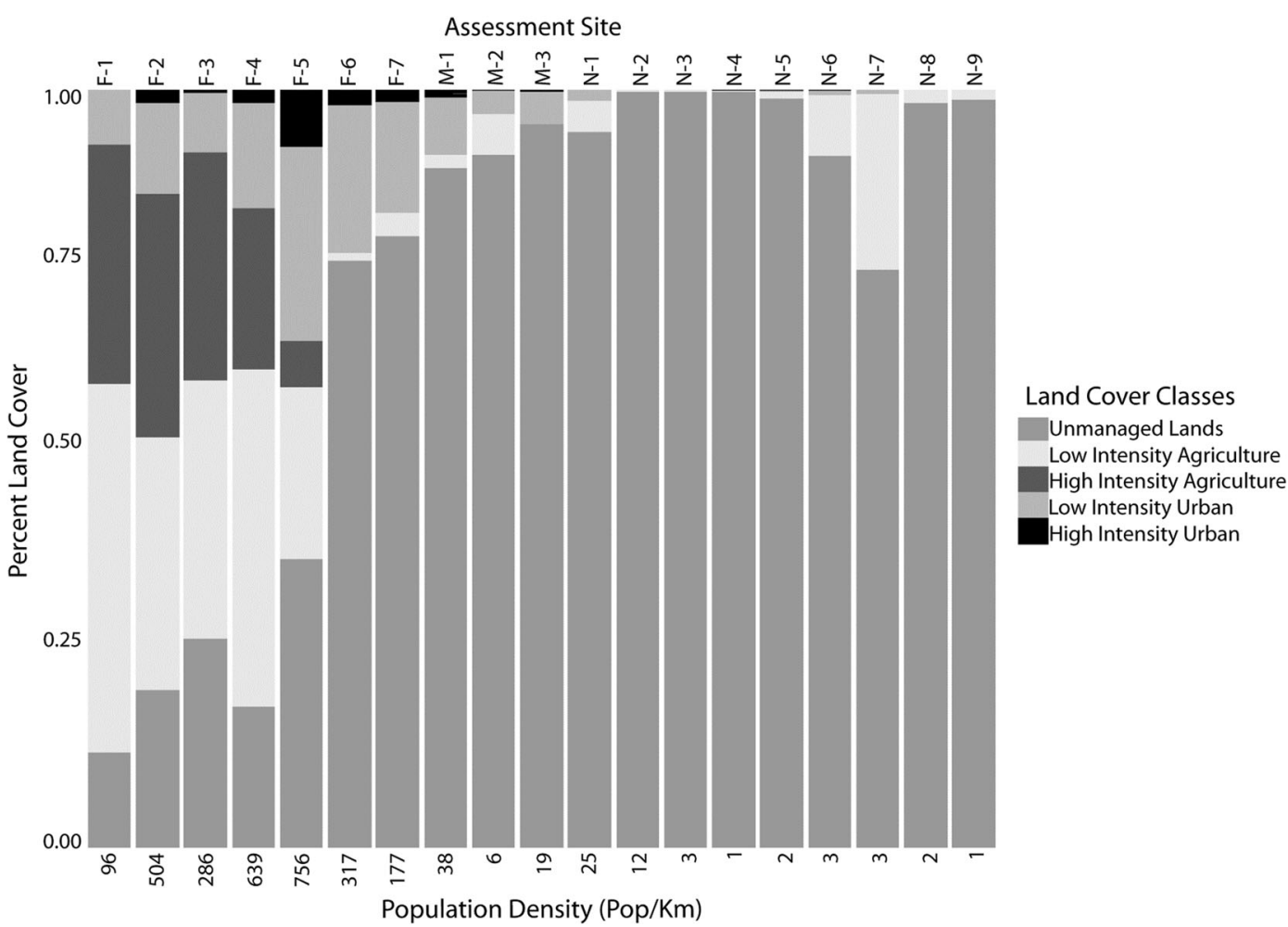

Fig. 2 Percent cover of land-cover classes and population density (Montana State Library 2011) for each assessment site (floodplain and buffer area combined)

ArcGIS 10.0 (ESRI 2011) and the R system for statistical computing (R Core Team 2013).

Multi-metric index case study

Multi-metric indices are composed of qualitative measures of the condition of biotic and abiotic structural attributes that, in combination, support ecological function or maintain ecosystem integrity. To create metrics, a score is assigned (e.g., 0-1, 1-100) to the attribute; to create an index, these metrics are combined in a manner that best describes the attribute's relative contribution to system function or integrity. The metric scores and index model are based on reference data, literature, and expert opinion of model developers to assess specific ecosystem aspects important to management (e.g., habitat, ecosystem services, or overall function). In practice, a robust landscape-scale floodplain assessment model may incorporate attributes from multiple spatial datasets, such as road densities, wetland inventories, soil databases, elevation, slope, and human population density. In this case study, for illustrated purposes only, we developed a simplified MMI with metrics derived from a single thematic map, the 2006 National Land Cover Database (NLCD), to specifically address aspects of uncertainty that arise from a single data source. For this case study, we followed MMI general protocols (e.g., Smith et al. 1995; Barbour et al. 1999; Stoddard et al. 2008) to develop a simplified tool to address the overall condition of native floodplain cover.

NLCD thematic classified maps were developed for the conterminous United States by a coalition of U.S. agencies (MRLC 2013) using Landsat Thematic Mapper (TM) data for the 1992 map (Vogelmann et al. 2001) and Landsat Enhanced Thematic Mapper+ (ETM+) data for maps from years 2001 (Homer et al. 2007), 2006 (Fry et al. 2011), and 2011 (Jin et al. 2013). From 2001 on, NLCD used a decision-tree-based supervised classification approach to create a land-cover classification scheme at a spatial resolution of $30 \mathrm{~m}$, followed by the aggregation of pixels to achieve a minimum mapping unit of approximately 0.40 ha, to assign pixels to one of 16 classes (Homer et al. 2004, 2007). The supporting NLCD literature also provided accuracy assessments in the form of a confusion matrix containing overall, producer's, and user's accuracy calculations that clearly 
articulated map classification error (MRLC 2013). These products do not require the map user to collect or process additional data; therefore, we applied the same limitation and did not collect additional site-specific accuracy data for this study beyond what was supplied with the NLCD product. Here, we used the 2006 NLCD classified map from Path 41 and Row 26 (MRLC 2013) clipped to our floodplain and buffer polygons for each of the 19 assessment areas.

\section{Landscape metrics}

For our landscape-scale MMI, we derived two metrics from the 2006 NLCD data: (1) a perturbation metric that assessed land-use intensity and (2) a fragmentation metric that measured land-cover configuration. Each metric was first calculated for the buffer and floodplain areas and then subsequently combined into the assessment index.

Perturbation metric for buffer and floodplain areas $\left(\right.$ Met $_{B P}$ and Met $\left._{F P}\right)$ The aerial extent of human-altered land cover within an assessment site is a commonly used indicator of the site's overall anthropogenic stressors (O’Neill et al. 1999; Tiner 2004; Brown and Vivas 2005). To extract this information from the NLCD categorical maps, 16 land-cover classes from the original map were binned into five major land-use groups that best represented the anthropogenic land-use disturbance gradient found within the study area (Table 1): (1) unmanaged lands, (2) low-intensity agriculture, (3) high-intensity agriculture, (4) low-intensity urban, and (5) high-intensity urban. Because we were developing an assessment of native floodplain cover condition, we treated all such cover as a single "unmanaged land" cover class.

For the purposes of this study, each of the five landcover groupings was subjectively weighted, based on expert opinion, to represent the degree of divergence from land cover that was characteristic of unperturbed conditions typical of Rocky Mountain valleys (Table 1). Within each assessment area, buffer $\left(M_{B P} t_{B P}\right)$ and floodplain $\left(M_{F P}\right)$ areas were separately scored using Eq. 1:

$M e t=\frac{\sum_{x=1}^{x}\left(\sum C_{L x}{ }^{*} w_{L x}\right)}{N}$

where the metric score (Met) for the buffer or floodplain assessment area is equal to the total raster cells per cover
Table 1 NCLD cover types binned to reflect a gradient of major land-use categories and the weighted sub-score assigned to each category, reflecting the gradient of land-use intensity used in the perturbation metric

\begin{tabular}{|c|c|}
\hline Buffer and floodplain land-use criteria & $\begin{array}{l}\text { Weighted } \\
\text { sub-score }\end{array}$ \\
\hline $\begin{array}{l}\text { Unmanaged land cover: land-cover characteristic } \\
\text { of Rocky Mountain floodplain systems, which } \\
\text { include open water, forest, shrub, herbaceous, } \\
\text { and wetlands cover classes. NCLD Codes } 11 \text {, } \\
12,41,42,43,52,71,90 \text {, and } 95\end{array}$ & 1.0 \\
\hline $\begin{array}{l}\text { Low-intensity agriculture: herbaceous areas used } \\
\text { for pasture and hay. NCLD code } 81\end{array}$ & 0.8 \\
\hline $\begin{array}{l}\text { High-intensity agriculture: cultivated row crops. } \\
\text { NCLD code } 82\end{array}$ & 0.5 \\
\hline $\begin{array}{l}\text { Low-intensity urban: developed open space and } \\
\text { low-intensity developed lands. NCLD codes } \\
21 \text { and } 22\end{array}$ & 0.2 \\
\hline $\begin{array}{l}\text { High-intensity urban: barren ground } \\
\text { (predominantly gravel mines, but also includes } \\
\text { to a much lesser extent cobble), as well as } \\
\text { medium- and high-intensity developed lands. } \\
\text { NCLD codes } 23,24 \text {, and } 31\end{array}$ & 0.0 \\
\hline
\end{tabular}

class $\left(C_{L x}\right)$ multiplied by the weighted sub-score for that class $\left(w_{L x}\right)$ from Table 1, summed across all classes $(x)$, then divided by the total cell count $(N)$ of the assessment area to obtain a score that ranges between 0.0 and 1.0. The closer the metric score is to 1.0 , the more likely the area has land-cover characteristics of an undisturbed system. A score closer to 0.5 represents agricultural land cover, and 0.0 represents an area dominated by urban land-cover.

\section{Habitat fragmentation metric for buffer and floodplain} areas $\left(\right.$ Met $_{B F}$ and Met $\left._{F F}\right)$ The above perturbation metrics assess the extent of human alteration. However, two sites with the same relative abundance of unmanaged land could provide different levels of structural support for native biota depending on the degree of fragmentation (Vogt et al. 2007). Our fragmentation metric measured the degree of continuity within landscape patterns (Gustafson 1998; O’Neill et al. 1999). We used a morphological spatial pattern analysis (MSPA) GIS tool (Joint Research Station 2014) to identify the extent of contiguous and isolated patches, perforations within those patches due to agriculture and urban areas, and the amount of edge between these managed and unmanaged lands. The MSPA input required a binary map consisting of unmanaged lands from Table 1 and a cover type called managed lands that was created by binning 
all agriculture and urban land-cover types in Table 1. The output of the MSPA tool was a map containing a mutually exclusive set of seven patch and edge structural classes within the floodplain and its buffer (Vogt et al. 2007; Soille and Vogt 2009; Suarez-Rubio et al. 2012): (1) core areas, (2) patch edges, (3) loops, (4) bridges, (5) branches, (6) islets, and (7) managed lands. Each structural class was subjectively assigned a weighted subscore based on an expert opinion that represented the degree of fragmentation or edge (Table 2). The structural class assignments were then clipped to each buffer and floodplain assessment site.

The fragmentation metric score for both the buffer $\left(M_{B F}\right)$ and floodplain $\left(M_{F F}\right)$ was calculated using Eq. 1, where total raster cells per MSPA structural class $\left(C_{L x}\right)$ at each site were determined and multiplied by the weighted sub-score $\left(w_{L x}\right)$ from Table 2 . The closer the metric score was to 1.0 , the more the likely the area had contiguous land-cover characteristic of an undisturbed

Table 2 Description of structure categories of the fragmented landscape and the weighted sub-score assigned to each category, reflecting the gradient of habitat quality used in the fragmentation metric

\begin{tabular}{|c|c|}
\hline Fragmentation structure & $\begin{array}{l}\text { Weighted } \\
\text { sub-score }\end{array}$ \\
\hline $\begin{array}{l}\text { Core areas - pixels of unmanaged lands inside of } \\
\text { a defined } 90-\mathrm{m} \text { ( } 3 \text { pixels) wide patch width } \\
\text { (pixel value from a post MSPA map are } 17, \\
\text { 117) }\end{array}$ & 1.0 \\
\hline $\begin{array}{l}\text { Patch edge - pixels of unmanaged lands that are } \\
\text { comprised of patch edge adjacent to managed } \\
\text { land-cover type (MSPA pixel value } 3,5,35, \\
67,103,105,135,167)\end{array}$ & 0.8 \\
\hline $\begin{array}{l}\text { Loop_-pixels that connect one patch of core } \\
\text { unmanaged lands to the same core area and are } \\
\text { completely made up of edge (MSPA pixel } \\
\text { value } 65,69,165,169)\end{array}$ & 0.6 \\
\hline $\begin{array}{l}\text { Bridge - pixels that connect one patch of core } \\
\text { unmanaged lands to another core area and are } \\
\text { completely made up of edge (MSPA pixel } \\
\text { value } 33,37,133,137)\end{array}$ & 0.6 \\
\hline $\begin{array}{l}\text { Branch - pixels that emanate from core, bridge, } \\
\text { or loops into managed lands and are } \\
\text { completely made up of edge (MSPA pixel } \\
\text { value } 1,101 \text { ) }\end{array}$ & 0.4 \\
\hline $\begin{array}{l}\text { Islet - pixels of unmanaged lands within a patch } \\
\text { of managed lands that is completely made up } \\
\text { of edge (MSPA pixel value } 9,109 \text { ) }\end{array}$ & 0.2 \\
\hline $\begin{array}{l}\text { Managed lands - all remaining pixels (MSPA } \\
\text { pixel value } 0,100 \text { ) }\end{array}$ & 0.0 \\
\hline
\end{tabular}

system; the closer to 0.0 , the more likely the area had a contiguous cover of managed land.

\section{Flathead river floodplain condition index}

Finally, we applied the index model (Eq. 2) to calculate the Flathead River floodplain habitat condition based on land-use intensity and habitat fragmentation:

Index $=\left(\left(\left(\operatorname{Met}_{B P}+\operatorname{Met}_{B F}\right) / 2\right)+\operatorname{Met}_{F P}+\operatorname{Met}_{F F}\right) / 3$

The condition of the buffer influences the condition of the floodplain (Allan 2004); therefore, we first averaged the buffer metrics $\left(\operatorname{Met}_{B P}\right.$ and $\left.M_{e t} t_{B F}\right)$. We then added that product to the floodplain metrics $\left(\operatorname{Met}_{F P}\right.$ and $\left.M e t_{F F}\right)$ and averaged the final product to provide a score between 0 and 1 . Scores closer to 0.0 represented a disturbed landscape and scores closer to 1.0 represented an intact ecosystem in excellent condition. This MMI provided a naive estimate of ecological conditions and was, in essence, the data collection component of the methods. The following data analysis methods address the impact of input map error on these results.

\section{Data analysis}

We addressed map misclassification effects on the MMI results by first reducing the map error from the original NLCD 2006 map (MRLC 2013) where possible without additional data collection. Then we incorporated the remaining unavoidable error into the metrics and index. Finally, we tested the bias of the naive MMI results when we incorporated this remaining error.

\section{Reducing uncertainty}

Two maps were created for the study area: (1) a land-use map used to assess the two perturbation metrics and (2) a binary map used to assess the two fragmentation metrics. Each map was created by aggregating thematic classes from the original data, thereby decreasing the thematic resolution of the original land cover classification. We aggregated the confusion matrix from the original accuracy assessment to create new confusion matrices for each new map. We also calculated the overall accuracy indices (Congalton and Green 2008) and compared these to the original 2006 NLCD accuracy indices (Fry et al. 2011) to determine the effects of changing thematic resolution on error. 


\section{Error simulation model}

Simulation models that use available confusion matrix information to account for misclassification error were developed in the 1990s (Fisher 1994; Hess and Bay 1997; Wickham et al. 1997). These models convert confusion of matrix user's or producer's accuracy information to a matrix of probabilities that inform the likelihood that an individual pixel is misclassified (Hess and Bay 1997). To meet the needs of potential resource managers, we created a matrix of probabilities based on user's accuracy. This "User's Probability Matrix" (UPM) is the proportion of locations classified in the map as $k_{i}$ (mapped pixels in class $(k)$ found across all reference columns $i$ through $n$ ) in a confusion matrix. For example, a hypothetical accuracy assessment was conducted on 100 randomly selected pixels mapped as forest $(k)$. These mapped pixels were checked against ground reference data; 90 pixels were determined to be forest $\left(k_{1}\right)$ and the remaining 10 were grassland $\left(k_{2}\right)$. From these hypothetical accuracy data, our UPM would assume that there was a $90 \%$ probability that any forested pixel in our map was actually forest and a $10 \%$ probability that it was actually grassland. Following this, we created UPMs for all thematic classes from the confusion matrices of both the perturbation landcover and binary fragmentation input maps (Tables 3 and 4).

In geographic studies, it is accepted that "nearby things are more similar than distant things" (Tobler 1970) and is the basis of most spatial autocorrelation studies and tools (Goodchild 2004). Because we did not collect additional data, we could not assess the spatial structure of the error. Therefore, in the second step of our simulation model, we incorporated an autocorrelation filter proposed by Wickham et al. (1997), which assumes an overall $10 \%$ difference in the classification error between the edge and interior pixels of a land-cover patch as a result of the influence of correlation between classified pixels (Congalton 1988). Applying a $10 \%$ spatial autocorrelation filter decreased the likelihood of classification errors within patches (salt and pepper errors) and also increased the likelihood of misclassifications near patch boundaries that were generally associated with errors resulting from mixed pixels and spatial misregistration. We applied a $3 \times 3$ moving window to locate the patch interior and edge in the two metric input maps. We then created filters that decreased the effects of the UPM by $5 \%$ for the interior pixels and increased the UPM by $5 \%$ at the patch edge. Additionally, we tested the Wickham et al. (1997) $10 \%$ autocorrelation modification against a $20 \%$ gradient to determine sensitivity of the simulated index results to these modifications.

Finally, to account for the remaining classification error, we applied a confusion frequency simulation Monte Carlo model (CFS) that takes advantage of the a priori error probabilities in the UPMs to create stochastic realizations of our perturbation and fragmentation input maps (Fisher 1994; Wickham et al. 1997). For each simulation, the CFS (1) identified cover class $k$ assigned to an individual map pixel, (2) drew a random variable from a uniform $(0,1)$ distribution, (3) adjusted the random variable with the autocorrelation filter, (4) determined the probabilities with all reference classes $\left(k_{1}-k_{n}\right)$ associated with cover class $k$ in the UPM, (5) assigned reference class $k_{i}$ to the output simulation for that cell based on the modified random value and user probability, and (6) repeated this process for all remaining classes to create a single simulated realization of the

Table 3 User probability matrix represents the likelihood that a pixel on the perturbation map is actually one of several ground-reference pixels (UPM is used to support the perturbation metric simulation)

\begin{tabular}{|c|c|c|c|c|c|}
\hline \multirow[b]{2}{*}{$\operatorname{Map}(k)$} & \multicolumn{5}{|c|}{ Reference $\left(k_{1}-k_{5}\right)$} \\
\hline & $\begin{array}{l}\text { Unmanaged } \\
\text { lands }\end{array}$ & $\begin{array}{l}\text { Low-intensity } \\
\text { agriculture }\end{array}$ & $\begin{array}{l}\text { High-intensity } \\
\text { agriculture }\end{array}$ & $\begin{array}{l}\text { Low-intensity } \\
\text { urban }\end{array}$ & $\begin{array}{l}\text { High-intensity } \\
\text { urban }\end{array}$ \\
\hline Unmanaged lands & 93.10 & 3.24 & 1.68 & 1.78 & 0.20 \\
\hline Low-intensity agriculture & 16.32 & 77.29 & 1.25 & 4.88 & 0.26 \\
\hline High-intensity agriculture & 4.02 & 5.50 & 88.05 & 2.40 & 0.03 \\
\hline Low-intensity urban & 19.96 & 5.10 & 5.14 & 65.40 & 4.40 \\
\hline High-intensity urban & 18.32 & 0.81 & 0.27 & 8.31 & 72.29 \\
\hline
\end{tabular}


Table 4 User probability matrix represents the likelihood that a pixel on the fragmentation map is actually one of several groundreference pixels (UPM is used to support the fragmentation metric simulations)

\begin{tabular}{lll}
\hline & Reference $\left(k_{1}-k_{2}\right)$ & \\
\hline Map $(k)$ & Unmanaged lands & Managed lands \\
Unmanaged lands & 93.10 & 6.90 \\
Managed lands & 10.39 & 89.61 \\
\hline
\end{tabular}

map. The CFS was conducted under the assumptions that each pixel was eligible for selection, and each pixel was independently classified (Hess and Bay 1997). With this process, 1000 Monte Carlo simulations were created for each map. For the fragmentation map, the MSPA tool was applied to each simulated output.

\section{Metric and index error assessment}

Following each simulation, we calculated a buffer and floodplain score for each metric (Eq. 1) and total index score (Eq. 2), generating a distribution of 1000 potential metrics and condition scores. It was assumed that each Monte Carlo simulation was an independent sample of that classification error and that the distribution of simulated metric and index scores represented a raw stochastic sample of the error model behavior. We did not make assumptions about the structure of the simulated distributions. Therefore, we chose a Wilcoxon signed rank test to test for differences between simulated site results. Additionally, to give an estimate of the potential variability in metric and index scores due to misclassification, $95 \%$ confidence intervals around the mean simulated score were derived from the 2.5th and 97.5th percentile of the metric and index scores distribution. The mean was chosen over the median as a conservative estimate of that distribution. Finally, the difference between original naive and simulated scores determined the bias of the naive assessment.

\section{Results}

Naive multi-metric index results

Typical of most MMIs, the initial results of this model were reported assuming that the input data was free from error (naive results). The final naive index scores articulated in the synoptic map (Fig. 3) closely matched the land-use/land-cover gradient across the study area (Fig. 2). Areas with intact, unmanaged lands scored in the upper index range $(>0.90)$, areas with a mix of lowintensity agriculture and unmanaged lands scored in the middle range ( $\sim 0.70-0.80)$, and areas with a mix of high- and low-intensity residential, agriculture, and unmanaged lands scored toward the lower end of the range $(0.50-0.70)$.

Map classification resolution

Aggregating land-cover groups lowered the resolution of thematic classifications in the original dataset from 16 classes to five classes for the perturbation map (Table 1) and two classes for the fragmentation map (Table 2). The 2006 NLCD map reported, at a national scale, an overall map accuracy of $78 \%$ for maps classified into their standard 16 Level 2 land-cover classes (Wickham et al. 2013). For the perturbation metrics, the original $16 \times 16$ confusion matrix collapsed into a $5 \times 5$ matrix, thereby decreasing thematic resolution and increasing overall accuracy to $90 \%$. For the fragmentation metrics, a $2 \times 2$ confusion matrix summarized the binary cover classes with an overall accuracy of $92 \%$.

Confusion frequency simulation results

For the error simulation model, user probability matrices (Tables 3 and 4) and autocorrelation filters were used in the confusion frequency simulations to provide a distribution of metrics and index scores, with $95 \%$ confidence intervals (Fig. 4). ${ }^{1}$ The simulated and naive results closely match the LULC gradient across the study area (Fig. 2). A pairwise Wilcoxon signed rank test was applied to all simulated index sites using both the 10 and $20 \%$ autocorrelation filter under the null hypothesis that there were no differences between the simulated sites. For sites N-2 and N-3, there was very strong evidence that they have the same mean index score ( $p$ value equal to 1.0 ) using the $10 \%$ filter, but there was strong evidence that all sites were different $(p$ value $<0.001$ ) using the $20 \%$ filter. Sites N-2 and N-3 both had naive score of 1.0 and all other naive scores were different. All remaining sites failed to support the null hypothesis,

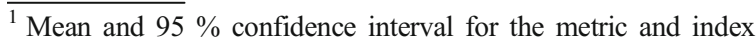
scores are available in the Appendix.
} 
Fig. 3 Synoptic map of Flathead River MMI scores

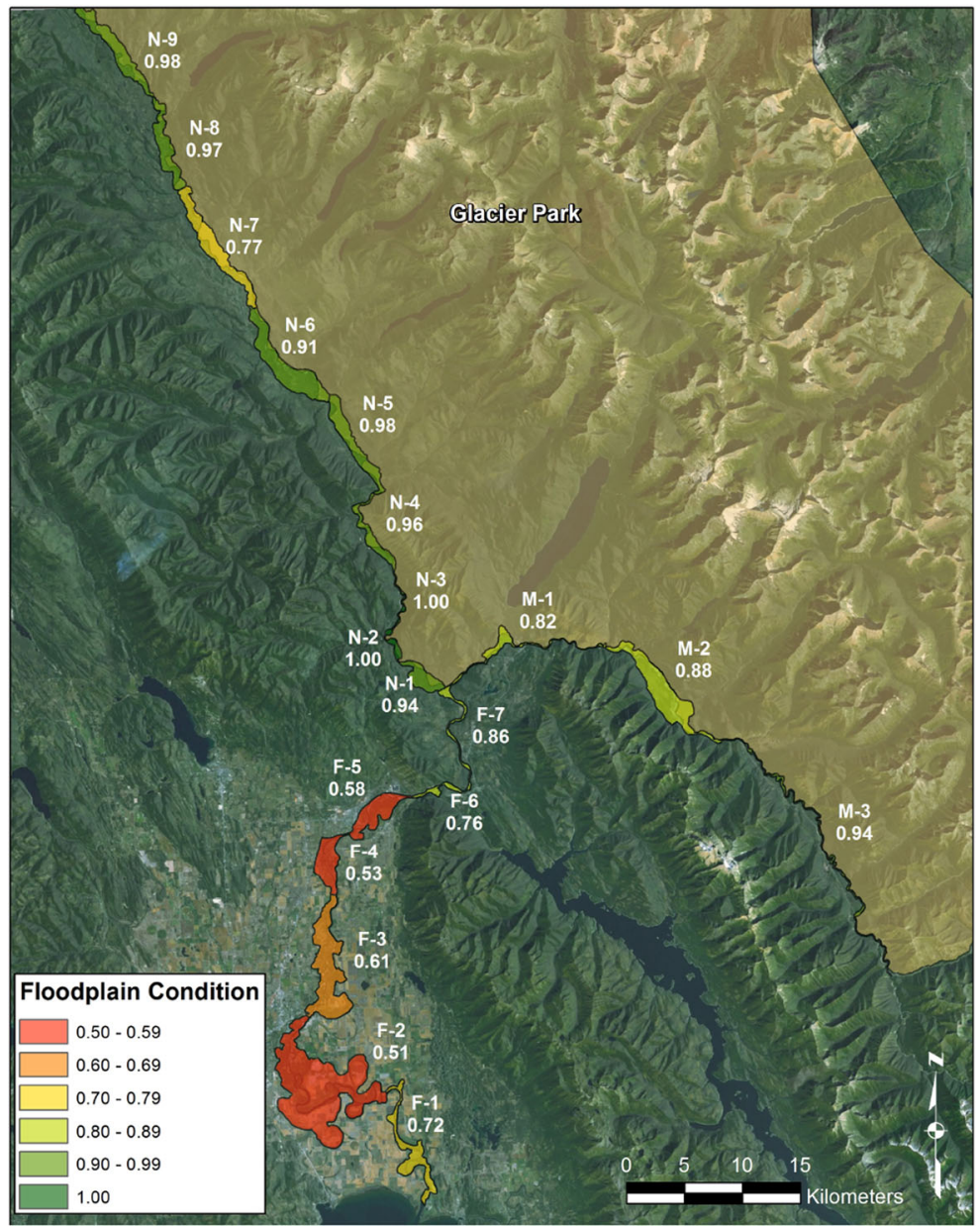

showing strong evidence of a difference between sites ( $p$ value $<0.001$ ) for both filters.

Sensitivity of simulated results to land cover

Information from two sites with very different land covers (N-3 and F-4) provided an illustrative example of assessment metrics and index responses to map misclassifications. Site N-3 is located adjacent to Glacier National Park and is classified in the original NLCD map as $99.7 \%$ unmanaged lands and $0.3 \%$ lowintensity agriculture (Fig. 5 and Table 5), with a human population density of 3 people per kilometer. Site F-4 is located in the Kalispell Valley and contains a portion of the town of Columbia Falls, MT and nearby agricultural activities. The original land-use intensity classified this site as $22.6 \%$ unmanaged lands, 42.2 and $19.8 \%$ lowand high-intensity agriculture, respectively, and 13.6 and $1.8 \%$ low- and high-intensity urban, respectively
(Fig. 5 and Table 5), with a human population density of 639 people per kilometer. The landscape pattern structural classes in the two sites (Table 6) also reflect the land-use distributions. Site N-3 received metric and index scores of 1.0 for the naive assessment consistent, with its nearly contiguous cover of unmanaged lands (Table 7). Site F-4 scored 0.61 for the naive index score consistent, with its urban and agricultural land use mixed with patchy unmanaged land cover.

For illustrative purposes, a single simulation was performed using the $10 \%$ autocorrelation filter to create the map realizations in Fig. 5. The simulated realization reflects potential errors along patch edges and salt and pepper errors within patches (Fig. 5). These simulated errors decreased the overall cover of unmanaged lands in Site N-3 by about $2.4 \%$ as these pixels were reassigned to low-intensity agriculture and urban land cover (Table 5). These reassigned pixels were peppered across the landscape (Fig. 5) and changed the 


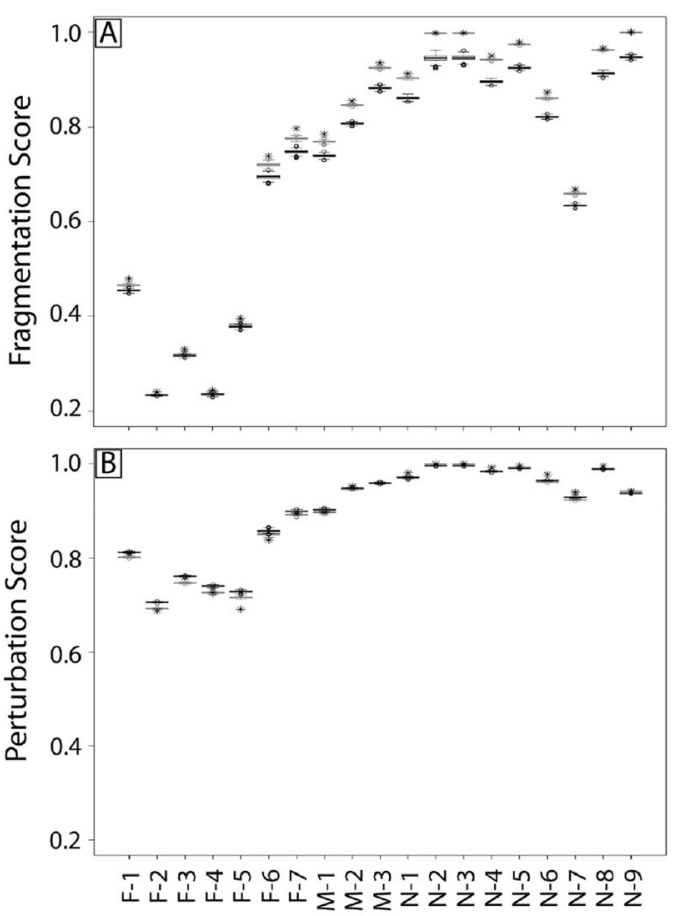

Site

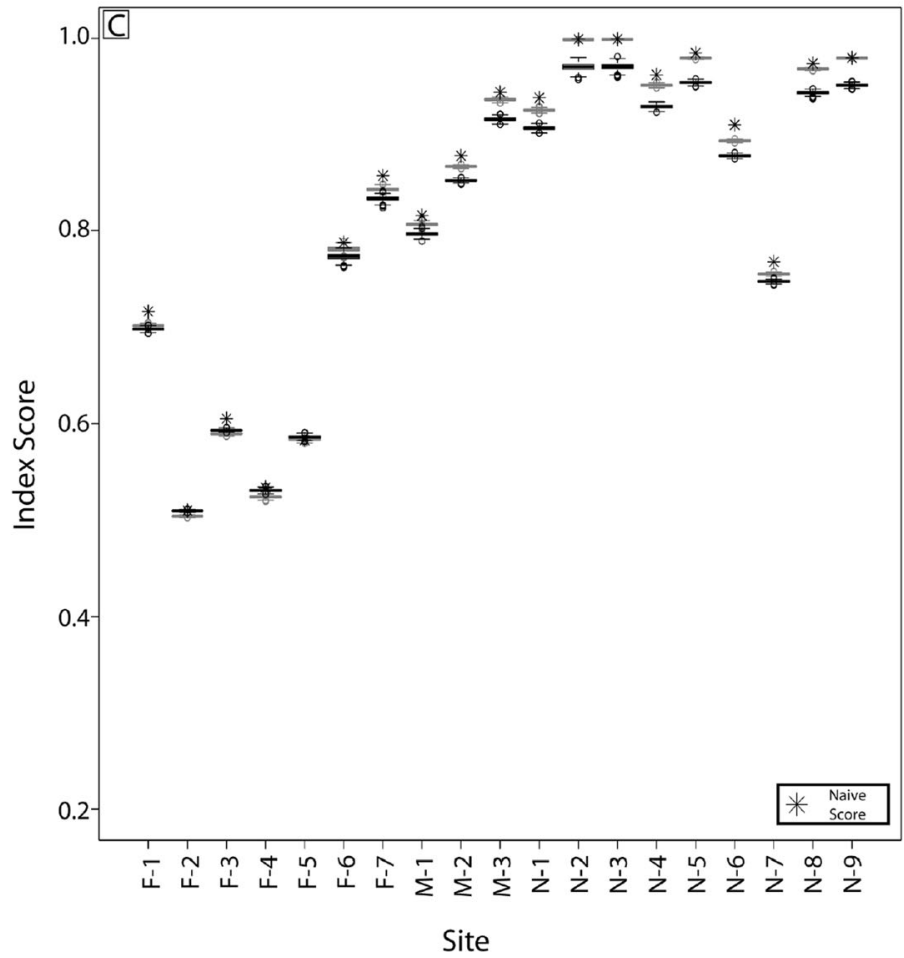

Fig. 4 Naive data (stars) and distribution boxplots of simulated fragmentation (a), perturbation (b) scores averaged from the buffer and floodplain results, and index (c) scores with $10 \%$ autocorrelation filters (black) and $20 \%$ autocorrelation filters (gray)

composition of the landscape pattern structural classes (Table 6). These changes resulted in a slight decrease in the buffer and floodplain perturbation metrics of 0.005 and 0.004 , respectively, a larger decrease in the buffer and floodplain fragmentation metric scores of 0.057 and 0.053 , respectively, and an overall decrease in the index from 1.0 to 0.97 (Table 7).

In the site F-4 simulation, numerous former agriculture and low-intensity urban pixels were reassigned to unmanaged lands, increasing the percent cover of unmanaged lands from 23 to $32 \%$. There was also a slight increase in the high-intensity urban cover from 2 to $4 \%$. These changes were along patch edges and peppered within the patches (Fig. 5). Although there was an increase in the cover of unmanaged lands, there was a decrease in continuous patch cover in these lands. Because the buffer areas originally had higher urban and agriculture cover, the redistribution of pixel classes in the simulation resulted in increased mean perturbation and fragmentation metric scores in the buffer by 0.030 and 0.011 , respectively. However, the floodplain originally had higher cover of unmanaged lands, and, as in site N-3, the redistribution of pixel classes in the simulated map decreased cover of unmanaged lands, which decreased both mean perturbation and fragmentation metric scores in the buffer by 0.009 and 0.018 , respectively. After the index calculation, changes in the metric scores were essentially eliminated, with no change between the naive and mean-simulated index that both scored 0.53 after rounding $(0.534$ and 0.531 , respectively; Table 7).

Metric and index bias

Bias between the naive index score and simulated results was determined using the $10 \%$ autocorrelation filter. The difference between the naive score and total distribution of simulated scores indicated a bias in the estimation of the index and metrics resulting from misclassification (Fig. 6). The fragmentation metric showed a greater bias in sites dominated by unmanaged lands (Fig. 6a). Within the perturbation metric, sites with heterogeneous land use had a negative bias between the naive and simulated results (Fig. 6b). Collectively, there was a positive bias between most naive and simulated index results, with the highest bias in sites dominated by unmanaged lands (Fig. 6c). Our model showed that the fragment metric had a positive average 

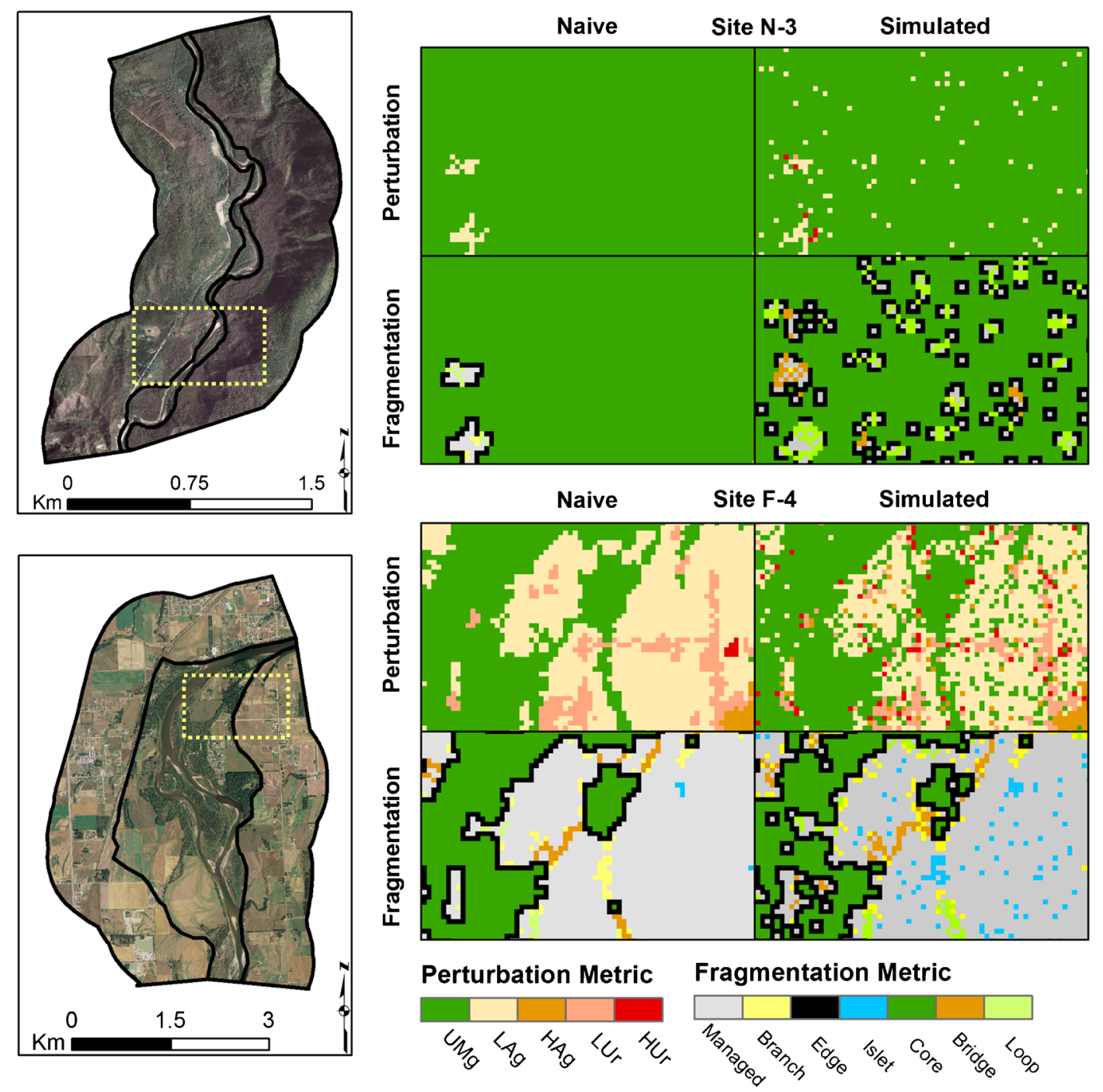

Fig. 5 Perturbation and fragmentation maps for sites N-3 (above) and F-4 (below). Sample maps represent area demarked by yellow box in site maps. Naive maps are derived from original NLCD data and simulated maps are a realization from a single iteration of the CFS error model

bias of $3.91 \%$, with a maximum of $6.08 \%$ for the floodplain area of N-6 and a minimum of $-18.22 \%$ for the buffer area of agriculture and urban site F-4. The perturbation metric had a negative average bias of

Table 5 Percent of land-cover classes from the original and simulated maps for sites N-3 and F-4

\begin{tabular}{|c|c|c|c|c|c|c|}
\hline & & \multicolumn{5}{|c|}{ Percent cover of perturbation classes } \\
\hline & & $\begin{array}{l}\text { Unmanaged } \\
\text { lands }\end{array}$ & $\begin{array}{l}\text { Low-intensity } \\
\text { agriculture }\end{array}$ & $\begin{array}{l}\text { High-intensity } \\
\text { agriculture }\end{array}$ & $\begin{array}{l}\text { Low-intensity } \\
\text { urban }\end{array}$ & $\begin{array}{l}\text { High-intensity } \\
\text { urban }\end{array}$ \\
\hline \multirow[t]{2}{*}{ Site F-4 } & Original & 22.67 & 42.23 & 19.76 & 13.56 & 1.79 \\
\hline & Simulation & 31.51 & 35.25 & 18.61 & 10.25 & 4.39 \\
\hline \multirow[t]{2}{*}{ Site N-3 } & Original & 99.73 & 0.27 & - & - & - \\
\hline & Simulation & 97.58 & 2.37 & - & 0.01 & 0.04 \\
\hline
\end{tabular}


Table 6 Percent of landscape pattern structural classes from the original and simulated maps for sites N-3 and F-4

\begin{tabular}{lllllllll}
\hline \multicolumn{7}{c}{ Percent cover of landscape pattern structures classes } & & \\
\cline { 3 - 8 } & & \multicolumn{1}{c}{ Core } & Edge & Loop & Bridge & Branch & Islet & Managed lands \\
\hline \multirow{2}{*}{ Site F-4 } & Original & 11.66 & 6.63 & 0.47 & 0.53 & 2.04 & 1.34 & 77.33 \\
& Simulation & 7.89 & 7.28 & 1.14 & 1.90 & 2.82 & 4.55 & 74.43 \\
Site N-3 & Original & 99.52 & 0.42 & 0.06 & - & - & - & - \\
& Simulation & 74.85 & 17.43 & 4.10 & 0.24 & 0.05 & - & 3.34 \\
\hline
\end{tabular}

$-0.41 \%$, with a maximum of $2.16 \%$ for the floodplain area of N-6 and a minimum of $-11.02 \%$ for the buffer area of urbanized site F-5. The naive index had positive average bias of about $2.39 \%$, with a maximum of $3.62 \%$ at site N-6 and a minimum of $-0.051 \%$ at site F-5.

\section{Discussion}

The confusion frequency simulation error model used here reveals that classification error affects assessment results in four important ways. First, naive results common to many large landscape assessment and monitoring efforts provide a biased estimate of habitat conditions compared to results that include errors. Second, depending on the land-cover composition of the assessment site, the magnitude and direction of this bias changes (Figs. 5 and 6 and Tables 6 and 7). Third, the magnitude and direction of the bias is independent for each metric (Fig. 6a, b). Finally, when these metrics are combined into an index, this bias is partially attenuated (Fig. $6 \mathrm{c}$ and Table 7).
All maps contain errors, and accuracy assessments provide insight into the extent and nature of misclassifications that are present. The confusion matrix is a foundation of classification accuracy assessment (Foody 2002). The NLCD 2006 map used here provides a confusion matrix associated with an accuracy assessment conducted at a continental scale only (Wickham et al. 2013). Fang et al. (2006) found that confusion matrices developed closer to the site of interest have much different error rates than regional or continental matrices. At any scale, the confusion matrix also has its own suite of inherent uncertainties. For instance, collection of reference data can also contain unmeasured sources of error (Foody 2002), and ground accuracy assessment teams may be inconsistent in the classification of mixed land cover in the assessment area or stratified random reference samples that may not capture spatially specific classification error (e.g., near patch edges). Additionally, although a confusion matrix is excellent at capturing thematic errors of omission and commission, it cannot capture all the non-thematic error that affects classification, such as misregistration of the image with ground data (Stehman 1997). Ultimately,

Table 7 Metric and index results for naive and simulated distribution for sites N-3 and F-4, including resulting bias

\begin{tabular}{|c|c|c|c|c|c|c|}
\hline & & \multicolumn{2}{|l|}{ Perturbation } & \multicolumn{2}{|l|}{ Fragmentation } & \multirow[t]{2}{*}{ Index } \\
\hline & & Buffer & Floodplain & Buffer & Floodplain & \\
\hline \multirow[t]{3}{*}{ Site F-4 } & Original & 0.62 & 0.84 & 0.06 & 0.42 & 0.53 \\
\hline & Simulation & $0.650( \pm 0.004)$ & $0.831( \pm 0.004)$ & $0.071( \pm 0.003)$ & $0.402( \pm 0.007)$ & $0.531( \pm 0.003)$ \\
\hline & Bias & -0.030 & 0.009 & -0.011 & 0.018 & -0.001 \\
\hline \multirow[t]{3}{*}{ Site N-3 } & Original & 1.00 & 1.00 & 1.00 & 1.00 & 1.00 \\
\hline & Simulation & $0.995( \pm 0.001)$ & $0.996( \pm 0.002)$ & $0.943( \pm 0.006)$ & $0.947( \pm 0.020)$ & $0.971( \pm 0.007)$ \\
\hline & Bias & 0.005 & 0.004 & 0.057 & 0.053 & 0.029 \\
\hline
\end{tabular}



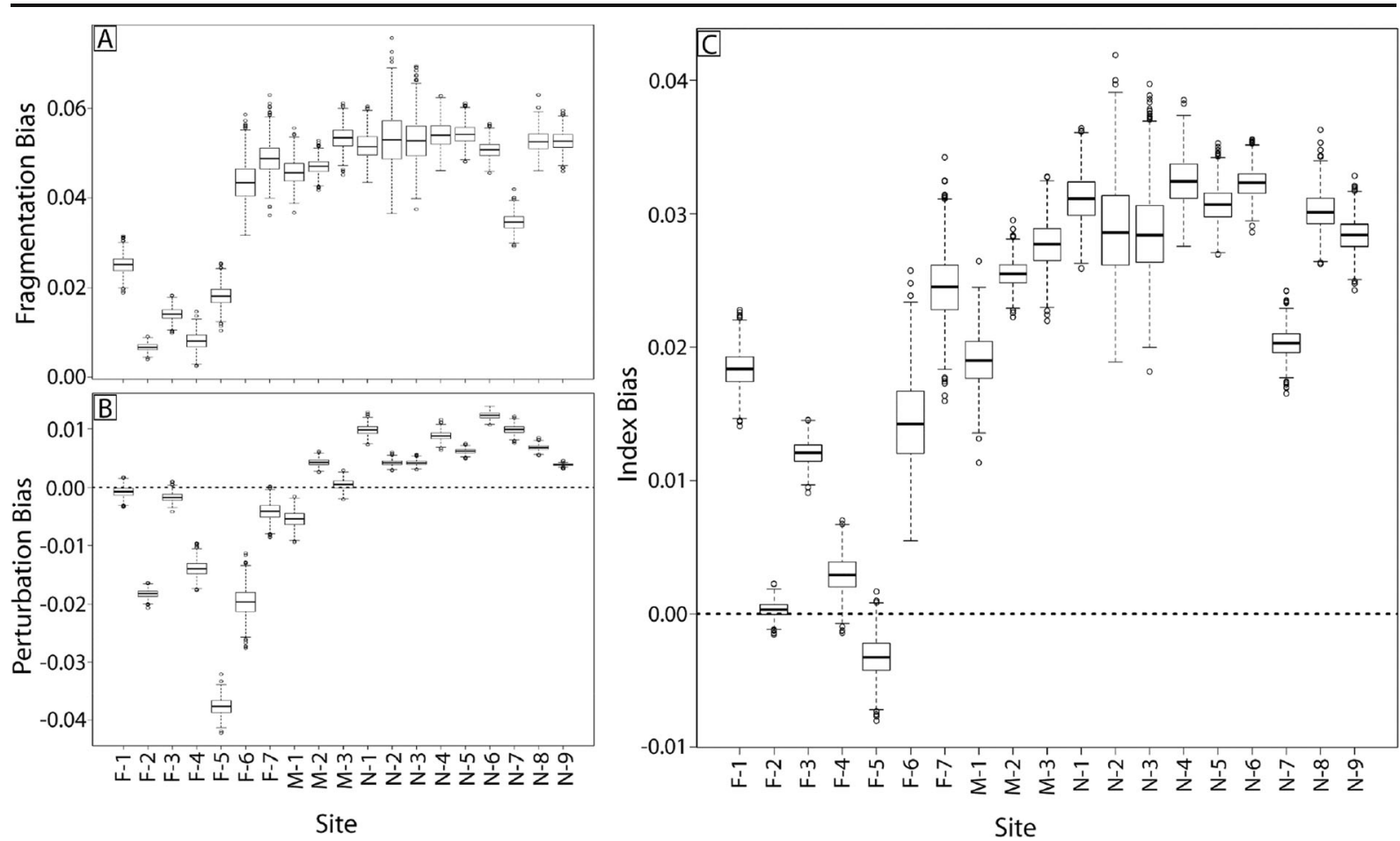

Fig. 6 Distribution boxplots of bias of fragmentation (a), perturbation (b) scores averaged from the buffer and floodplain results, and index scores (c) for each assessment site

obtaining a reliable confusion matrix and associated indices can be problematic (Pontius and Millones 2011). However, it currently remains the core accuracy assessment tool (Foody 2002). Regardless, the map user will be limited to the data provided unless they conduct their own accuracy assessment effort.

Confusion frequency simulation error models developed for categorical thematic maps use available information from the confusion matrix to account for errors resulting from misclassification (Fisher 1994; Hess and Bay 1997; Wickham et al. 1997; Langford et al. 2006). In the simulated realizations used here, pixels within the homogeneous unmanaged land cover are reclassified according to the user probability matrix, resulting in increased land-use heterogeneity and, thereby, lower assessment metric and index scores (Fig. 4). In contrast, sites with heterogeneous land uses are remixed to an alternative version of heterogeneity, resulting in a simulated map that may have higher or lower assessment scores depending on the ratio and spatial composition of managed to unmanaged lands in the original map (Figs. 2 and 4). Although this assessment did not have sites of homogeneous urban cover, such sites would be reclassified to have a higher cover of unmanaged lands according to the UPMs in Tables 3 and 4, which would raise the assessment metric and index scores.

Reducing error where possible is a first step to addressing uncertainty. The initial dataset provided an overall accuracy of $78 \%$ for the 2006 NLCD continental-scale accuracy assessment. To create our assessment model, it was necessary to aggregate several of the land-cover categories into land-use groups, thereby lowering map classification resolution and resulting in increased overall accuracy to $90 \%$ for the perturbation map and $92 \%$ for the binary map. There were no radical departures between the between the naive and simulated results (Fig. 4), likely because of the input maps' higher accuracies. However, if an alternative arrangement of the thematic input data were required to measure other aspects of the ecosystem, then the results would be different.

Because we intentionally did not collect site-specific map accuracy data, we remain ignorant of the spatial structure of the map error. However, we recognize that spatial autocorrelation affects the extent of misclassification within and between land-cover patches 
(Congalton 1988). When applied here, the $10 \%$ spatial autocorrelation filter decreases the randomly located misclassifications within patches (salt and pepper error) and increases the misclassifications near patch boundaries. However, when applying the $20 \%$ autocorrelation filter, this effect is exaggerated, resulting in simulated results that trend toward the naive results and an overall decrease in bias between the naive and simulated metric and index scores (Fig. 4). Without collecting the required local reference data to test the true relationships with autocorrelations, we felt it was best to be conservative in the face of uncertainty (Armstrong 2001) and applied the $10 \%$ autocorrelation filter to the CFS error model. Ultimately, without an estimate of the structure of the spatial error, our simulation will likely contain its own misclassifications. However, our simulated values of ecological condition provide a more conservative estimate than our naive model results.

A remote-sensing product, such as the NLCD (MRLC 2013), is an appealing source of information for regional ecosystem assessment and monitoring. The NLCD provides thematic land-cover information and accuracy assessments that do not require the end-user to conduct the expensive and time-consuming (Foody 2002; Fang et al. 2006) necessary steps to process and analyze raw Landsat imagery or to collect additional accuracy assessment data (Homer et al. 2004, 2007). The above approach is not intended to be an assessment of the quality of the NLCD product; rather, it is intended to serve as a straightforward approach that could be used with any number of land-cover products.

Because we were interested in the uncertainty effects arising from a single source of input data and its impact on model outcomes, this case study did not address the other important sources of uncertainty that can manifest in the context and structure of ecosystem models (Walker et al. 2003; Refsgaard et al. 2007). Context refers to conditions and circumstances that frame the problem of interest from the perspective of the end-user (Walker et al. 2003). Our simplified case study assessed the overall condition of native floodplain habitats, which determined binning of the thematic data, weighting of the metrics sub-index scores, and the structure of the multi-metric model. If the model-building team and resource managers decide that other aspects of the system are important, such as the condition of floodplain wetlands, backwater channels, or forests, then structure of the binned input data would be different. Even with the model we chose, there were uncertainties built in to its structure and relationships between input data (including size of buffer, scale of assessment reaches, and binning of thematic data), metrics derived from these data, and their sub-index scores (Cressie et al. 2009). This epistemic uncertainty, due to imperfect knowledge, can be reduced through an increased understanding of how the modeled system works or refining of input data and its analysis. We recognize that any modeling effort should account for epistemic uncertainty due to model structure, and these efforts should be communicated to the end-user (Walker et al. 2003; Janssen et al. 2005; Refsgaard et al. 2007). However, for this effort, we were only interested in stochastic uncertainty due to inherent variability of the input data and its impact on the model outcome. Therefore, we accepted our simplified multimetric case study for its consistent, albeit imperfect, structure.

Implications of land-cover misclassification to resource decisions

Millions of dollars are spent annually in the U.S. on ecological monitoring, assessment, and restoration (Lovett et al. 2007; USEPA 2012). Landscape metrics and indices assist decision makers with allocating limited funds by prioritizing monitoring, protection, and restoration efforts (Hyman and Leibowitz 2000; Lausch and Herzog 2002; Steel et al. 2004; Hierl et al. 2008). Landscape metrics and indices are also frequently used to refine or test finer-scale monitoring and assessment tools (Stein et al. 2009; Rains et al. 2013). Also, quality thresholds are frequently used to trigger management actions and addressing the effects of classification error on assessment metric and index scores can assist decision makers in determining which sites are above or below such thresholds. However, the influence of classification accuracy on landscape indices has been largely ignored (Shao and $\mathrm{Wu} 2008$ ). Without error assessment, applications of large landscape models for conservation decisions or finer-scale model development may be flawed.

Critical examinations of index-based approaches in the scientific literature (May 1985; Seegert 2000; Green and Chapman 2011) have addressed the shortcomings of metrics and indices in terms of sensitivity, calibration, and information loss. What are not seen in the literature are criticisms from the intended end-users of such models. Even if the scientific criticisms are accounted for, these models may fall into disuse when passed from 
scientist to end-user due to the overall lack of confidence in the assessment tool that results from uncertainty in its input data, the metrics it uses, and the output it creates. Tracking and reporting uncertainty is considered best practice in most remote-sensing and quantitative-modeling efforts. Although scientists have a general operational definition of uncertainty based on a model's statistical properties, when applied to resource management, uncertainty in scientific outcomes potentially translates into a state-of-confidence that the decision maker has in its application. Policy makers view these uncertainties in association with their management goals and priorities (Walker et al. 2003).

The confusion frequency simulation error model used here is dependent on user probability matrices derived from the binned confusion matrix. If the original thematic map was binned differently to suit an assessment of different system attributes, then the UPMs, subsequent simulated realization of the maps, and resulting simulated metric and index would also change. By applying the CFS error model, we establish a distribution of potential metric and index scores and, therefore, bind the effect of the classification error. With our case study, the simulated results did not diverge greatly from the naive results (Fig. 4c). However, there are a few points of caution that should be kept in mind. First, the measured differences between the naive and simulated results of both the metrics and index imply that using naive results alone can be problematic. Second, although the CFS error model provides insight into potential land-cover realizations, changes in simulated assessment scores in area of homogeneous cover (e.g., Fig. 5 site N-3) can be also problematic. Finally, given the assessment scale and data resolution, both our naive and simulated results can distinguish between sites across the range of land use. However, to distinguish between sites with similar land use would require a different assessment tool to address local-scale disturbances. Nonetheless, providing information about error to the decision makers helps improve the state-of-confidence in the assessment tool.

Nevertheless, merely providing information on error within the model results does not necessarily assist the end-user in their ability to absorb that uncertainty into their decision. Interpretation tools, such as fuzzy sets and fuzzy operational rules, make it possible to formalize the knowledge of experts to provide information to assist the model end-user in areas where numerical data may be limited (Uricchio et al. 2004). Still, applying well-established approaches to characterize and interpret the degrees of uncertainty within data (e.g., rough sets, fuzzy sets, probability density functions) do not guarantee the assessment model will be used. As a tool, index-based assessments exist in the difficult area between science and policy (Turnhout et al. 2007), and scientists and model builders are not necessarily involved in the ultimate use of their product as a decision tool. Ideally, during the assessment tool development process, the science team works with the policy and stakeholders team to create a product that accounts for uncertainty and clearly articulates the limitations of the model in a manner that is easily understood by the end-user, so that the degrees and types of uncertainty in the model output can be reasonably absorbed into their decision process in a straightforward manner (Niemi and McDonald 2004; Turnhout et al. 2007).

Many of the historical advancements of assessment are well documented in the scientific literature. However, much of its development and application occurred in management settings (e.g., Adamus et al. 1987; Brinson et al. 1994; Hawkins et al. 2000; Hauer et al. 2002). Today, there are over 400 contemporary biological and structural assessment methods applied across a suite of environmental problems (Bartoldus 1999; Diaz et al. 2004; Fennessy et al. 2004; Böhringer and Jochem 2007). As the ease of access to classified Landsat products and geographic information tools increase, the number of landscape assessment metrics will likely expand as tools are developed to address a multitude of landscape-scale environmental problems. Each of these new metrics will have their unique sensitivity to classification error. For instance, several authors have already found that some landscape metrics are more sensitive to classification error than others (Hess and Bay 1997; Wickham et al. 1997; Shao et al. 2001; Langford et al. 2006). As our work has shown, metrics also respond differently to classification error across disturbance gradients associated with changes in LULC in each assessment site. Incorporating error sensitivity tests into the assessment model building process can help determine the level of classification errors that can be tolerated for existing and new landscape metrics and subsequent indices (Shao and $\mathrm{Wu}$ 2008). 


\section{Conclusion}

Our results elucidate the potential bias between the more common naive approach to ecological assessment and an approach that includes error. We show an increase in overall map accuracy as the 16 land-cover categories in the original NLCD thematic map was aggregated into the five land-use groups for the perturbation map and the two land-cover groups for our fragmentation map. These aggregated maps inform probabilities of misclassification within a confusion frequency simulation error model. The assessment metrics within our multi-metric index respond in different ways to map error depending on the land-cover pattern of each assessment site. When combined into an index, it appears that naive scores slightly over-estimate ecological quality within sites comprised of contagious unmanaged lands that are associated with higher quality floodplains. Additionally, the naive scores could potentially underestimate the quality in more disturbed sites comprised of heterogeneous land uses. Naive approaches are easier to implement. However, recognizing that using such an approach is biased may help with the end-user's state-ofconfidence in the landscape assessment tool.

Acknowledgments We are very thankful to Dr. James Wickham of the U.S. EPA for his assistance with the NLCD data and to Dr. Guofeng Cao of Texas Tech University for his assistance on error simulation models. Also, we would like to thank Dr. Peter Vogt of the European Joint Research Centre for providing an executable of his MSPA fragmentation tool. Senior author W. J. Kleindl was supported in part by the National Science Foundation EPSCoR program under Grant \#NSF-IIA-1443108 and by the Flathead Lake Biological Station's Limnology Professorship of F. R. Hauer. Any opinions, findings, conclusions, or recommendations expressed in this material are those of the author(s) and do not necessarily reflect the views of the National Science Foundation.

\section{Appendix}

Confusion frequency simulation metric results Using the confusion frequency simulation, each pixel retained its class assignment or was reassigned according to an outcome of a uniform random draw between 0 and 1 that was adjusted by the spatial autocorrelation filter. One thousand simulations of each metric were performed and an index score was calculated per iteration. These simulations provide a distribution of index scores and a $95 \%$ confidence interval given the probabilities of class assignment (Tables 8, 9, and 10). The simulated data are provided in three significant digits to demonstrate the limitations of confidence intervals. The naive results are provided for comparison purposes and are reported in two significant digits, which is a general precision standard for most 0-1 MMI results.

Table 8 Perturbation metric results and confidence intervals from the 1000 Monte Carlo confusion frequency simulations and naive results for comparison

\begin{tabular}{|c|c|c|c|c|c|c|c|c|}
\hline \multirow[b]{2}{*}{ Site } & \multicolumn{3}{|c|}{ Buffer perturbation } & \multirow[t]{2}{*}{ Naive score } & \multicolumn{3}{|c|}{ Floodplain perturbation } & \multirow[t]{2}{*}{ Naive score } \\
\hline & $2.50 \%$ & $50 \%$ & $97.50 \%$ & & $2.50 \%$ & $50 \%$ & $97.50 \%$ & \\
\hline F-1 & 0.705 & 0.707 & 0.709 & 0.69 & 0.914 & 0.917 & 0.920 & 0.93 \\
\hline $\mathrm{F}-2$ & 0.620 & 0.622 & 0.624 & 0.58 & 0.788 & 0.790 & 0.791 & 0.79 \\
\hline F-3 & 0.658 & 0.660 & 0.662 & 0.64 & 0.861 & 0.863 & 0.865 & 0.88 \\
\hline $\mathrm{F}-4$ & 0.646 & 0.650 & 0.653 & 0.62 & 0.827 & 0.831 & 0.835 & 0.84 \\
\hline F-5 & 0.652 & 0.655 & 0.659 & 0.59 & 0.798 & 0.802 & 0.806 & 0.79 \\
\hline F-6 & 0.856 & 0.859 & 0.862 & 0.83 & 0.847 & 0.857 & 0.865 & 0.85 \\
\hline F-7 & 0.873 & 0.875 & 0.877 & 0.86 & 0.919 & 0.925 & 0.930 & 0.93 \\
\hline M-1 & 0.939 & 0.941 & 0.942 & 0.94 & 0.860 & 0.865 & 0.870 & 0.86 \\
\hline M-2 & 0.981 & 0.982 & 0.982 & 0.98 & 0.912 & 0.914 & 0.917 & 0.92 \\
\hline M-3 & 0.965 & 0.966 & 0.967 & 0.96 & 0.948 & 0.951 & 0.954 & 0.95 \\
\hline
\end{tabular}


Table 8 (continued)

\begin{tabular}{|c|c|c|c|c|c|c|c|c|}
\hline \multirow[b]{2}{*}{ Site } & \multicolumn{3}{|c|}{ Buffer perturbation } & \multirow[t]{2}{*}{ Naive score } & \multicolumn{3}{|c|}{ Floodplain perturbation } & \multirow[t]{2}{*}{ Naive score } \\
\hline & $2.50 \%$ & $50 \%$ & $97.50 \%$ & & $2.50 \%$ & $50 \%$ & $97.50 \%$ & \\
\hline $\mathrm{N}-1$ & 0.977 & 0.979 & 0.980 & 0.98 & 0.960 & 0.963 & 0.966 & 0.98 \\
\hline $\mathrm{N}-2$ & 0.994 & 0.995 & 0.996 & 1.00 & 0.994 & 0.996 & 0.997 & 1.00 \\
\hline $\mathrm{N}-3$ & 0.994 & 0.995 & 0.995 & 1.00 & 0.994 & 0.996 & 0.998 & 1.00 \\
\hline $\mathrm{N}-4$ & 0.994 & 0.994 & 0.995 & 1.00 & 0.969 & 0.972 & 0.975 & 0.99 \\
\hline N-5 & 0.992 & 0.992 & 0.993 & 1.00 & 0.985 & 0.987 & 0.988 & 0.99 \\
\hline N-6 & 0.979 & 0.979 & 0.980 & 0.99 & 0.947 & 0.949 & 0.951 & 0.97 \\
\hline $\mathrm{N}-7$ & 0.961 & 0.962 & 0.963 & 0.97 & 0.894 & 0.897 & 0.899 & 0.91 \\
\hline $\mathrm{N}-8$ & 0.995 & 0.995 & 0.996 & 1.00 & 0.979 & 0.981 & 0.982 & 0.99 \\
\hline N-9 & 0.880 & 0.881 & 0.881 & 0.88 & 0.993 & 0.994 & 0.994 & 1.00 \\
\hline
\end{tabular}

Table 9 Fragmentation metric results and confidence intervals from the 1000 Monte Carlo confusion frequency simulations and naive results for comparison

\begin{tabular}{|c|c|c|c|c|c|c|c|c|}
\hline \multirow[b]{2}{*}{ Site } & \multicolumn{3}{|c|}{ Buffer fragmentation } & \multirow[t]{2}{*}{ Naive score } & \multicolumn{3}{|c|}{ Floodplain fragmentation } & \multirow[t]{2}{*}{ Naive score } \\
\hline & $2.50 \%$ & $50 \%$ & $97.50 \%$ & & $2.50 \%$ & $50 \%$ & $97.50 \%$ & \\
\hline F-1 & 0.165 & 0.168 & 0.170 & 0.17 & 0.733 & 0.740 & 0.747 & 0.79 \\
\hline $\mathrm{F}-2$ & 0.077 & 0.079 & 0.081 & 0.07 & 0.387 & 0.390 & 0.392 & 0.41 \\
\hline F-3 & 0.092 & 0.094 & 0.097 & 0.09 & 0.535 & 0.540 & 0.545 & 0.57 \\
\hline $\mathrm{F}-4$ & 0.068 & 0.071 & 0.074 & 0.06 & 0.395 & 0.402 & 0.409 & 0.42 \\
\hline F-5 & 0.251 & 0.255 & 0.260 & 0.26 & 0.494 & 0.501 & 0.508 & 0.53 \\
\hline F-6 & 0.709 & 0.715 & 0.722 & 0.75 & 0.657 & 0.676 & 0.692 & 0.72 \\
\hline F-7 & 0.713 & 0.717 & 0.722 & 0.76 & 0.766 & 0.780 & 0.792 & 0.83 \\
\hline M-1 & 0.845 & 0.849 & 0.852 & 0.90 & 0.620 & 0.631 & 0.640 & 0.67 \\
\hline M-2 & 0.920 & 0.924 & 0.928 & 0.98 & 0.685 & 0.691 & 0.697 & 0.73 \\
\hline M-3 & 0.893 & 0.896 & 0.899 & 0.95 & 0.857 & 0.866 & 0.876 & 0.92 \\
\hline N-1 & 0.898 & 0.905 & 0.912 & 0.96 & 0.807 & 0.817 & 0.826 & 0.87 \\
\hline $\mathrm{N}-2$ & 0.932 & 0.942 & 0.952 & 1.00 & 0.925 & 0.947 & 0.967 & 1.00 \\
\hline N-3 & 0.937 & 0.943 & 0.949 & 1.00 & 0.926 & 0.947 & 0.965 & 1.00 \\
\hline N-4 & 0.937 & 0.942 & 0.947 & 0.99 & 0.838 & 0.849 & 0.859 & 0.90 \\
\hline N-5 & 0.933 & 0.938 & 0.942 & 0.99 & 0.903 & 0.911 & 0.918 & 0.97 \\
\hline N-6 & 0.890 & 0.895 & 0.899 & 0.95 & 0.743 & 0.749 & 0.754 & 0.80 \\
\hline N-7 & 0.804 & 0.809 & 0.813 & 0.85 & 0.454 & 0.460 & 0.465 & 0.48 \\
\hline N-8 & 0.939 & 0.945 & 0.949 & 1.00 & 0.873 & 0.881 & 0.889 & 0.93 \\
\hline N-9 & 0.941 & 0.946 & 0.951 & 1.00 & 0.940 & 0.947 & 0.954 & 1.00 \\
\hline
\end{tabular}


Table 10 Index results and confidence intervals from the 1000 Monte Carlo confusion frequency simulations and naive results for comparison

\begin{tabular}{lllll}
\hline Site & \multicolumn{3}{l}{ Simulated index score } & \multirow{2}{*}{ Naive index results } \\
\cline { 2 - 4 } & $2.50 \%$ & $50 \%$ & $97.50 \%$ & \\
\hline F-1 & 0.695 & 0.698 & 0.701 & 0.716 \\
F-2 & 0.509 & 0.510 & 0.511 & 0.510 \\
F-3 & 0.591 & 0.593 & 0.595 & 0.605 \\
F-4 & 0.528 & 0.531 & 0.534 & 0.534 \\
F-5 & 0.583 & 0.586 & 0.589 & 0.583 \\
F-6 & 0.767 & 0.773 & 0.779 & 0.788 \\
F-7 & 0.828 & 0.833 & 0.838 & 0.858 \\
M-1 & 0.793 & 0.797 & 0.800 & 0.816 \\
M-2 & 0.851 & 0.853 & 0.855 & 0.878 \\
M-3 & 0.913 & 0.916 & 0.920 & 0.944 \\
N-1 & 0.903 & 0.907 & 0.911 & 0.938 \\
N-2 & 0.963 & 0.970 & 0.977 & 0.999 \\
N-3 & 0.963 & 0.971 & 0.977 & 0.999 \\
N-4 & 0.926 & 0.930 & 0.933 & 0.962 \\
N-5 & 0.951 & 0.954 & 0.957 & 0.985 \\
N-6 & 0.876 & 0.878 & 0.881 & 0.911 \\
N-7 & 0.745 & 0.747 & 0.749 & 0.768 \\
N-8 & 0.941 & 0.944 & 0.946 & 0.974 \\
N-9 & 0.949 & 0.951 & 0.954 & 0.980 \\
\hline
\end{tabular}

Open Access This article is distributed under the terms of the Creative Commons Attribution 4.0 International License (http:// creativecommons.org/licenses/by/4.0/), which permits unrestricted use, distribution, and reproduction in any medium, provided you give appropriate credit to the original author(s) and the source, provide a link to the Creative Commons license, and indicate if changes were made.

\section{References}

Adamus, P. R., Clairain, E. J., Smith, R. D., \& Young, R. E. (1987). Wetland evaluation technique. Volumes I and II. Vicksburg MS: US Army Engineers Waterways Experiment Station.

Allan, J. D. (2004). Landscapes and riverscapes: the influence of land use on stream ecosystems. Annual Review of Ecology, Evolution, and Systematics, 35, 257-284. doi:10.1146/ annurev.ecolsys.35.120202.110122.

Armstrong, J. S. (2001). Principles of forecasting: a handbook for researchers and practitioners. New York: Springer.
Barbour, M. T., Gerritsen, J., Snyder, B. D., \& Stribling, J. B. (1999). Rapid bioassessment protocols for use in streams and wadeable rivers: periphyton, benthic macroinvertebrates and fish. Second edition. (No. EPA 841-B-99-002). Washington, D.C.: U.S. Environmental Protection Agency; Office of Water.

Bartoldus, C. C. (1999). A comprehensive review of wetland assessment procedures: a guide for wetland practitioners. St. Michaels, Maryland: Environmental Concern Incorporated.

Böhringer, C., \& Jochem, P. E. (2007). Measuring the immeasurable-a survey of sustainability indices. Ecological Economics, 63(1), 1-8.

Brinson, M. M., Kruczynski, W., Lee, L. C., Nutter, W. L., Smith, R. D., \& Whigham, D. F. (1994). Developing an approach for assessing the functions of wetlands. In W. J. Mitsch (Ed.), Global wetlands: old world and new (pp. 615-624). Amsterdam, Netherlands: Elsevier.

Brooks, R. P., Wardrop, D. H., \& Bishop, J. A. (2004). Assessing wetland condition on a watershed basis in the Mid-Atlantic Region using synoptic land-cover maps. Environmental Monitoring and Assessment, 94(1-3), 9-22.

Brown, M. T., \& Vivas, M. B. (2005). Landscape development intensity index. Environmental Monitoring and Assessment, 101(1-3), 289-309.

Collins, J. N., Stein, E. D., Sutula, M., Clark, R., Fetscher, A. E., Grenier, L., et al. (2008). California Rapid Assessment Method (CRAM) for wetlands, v. 5.0.2. San Francisco, CA: San Francisco Estuary Institute. http://www.cramwetlands. org/documents/2008-09-30_CRAM 205. Accessed 21 May 2014.

Congalton, R. G. (1988). Using spatial autocorrelation analysis to explore the errors in maps generated from remotely sensed data. Photogrammetric Engineering and Remote Sensing (USA), 54(5), 587-592.

Congalton, R. G., \& Green, K. (2008). Assessing the accuracy of remotely sensed data: principles and practices ( $2 \mathrm{nd}$ ed.). Boca Raton: CRC press.

Cressie, N., Calder, C. A., Clark, J. S., Hoef, J. M. V., \& Wikle, C. K. (2009). Accounting for uncertainty in ecological analysis: the strengths and limitations of hierarchical statistical modeling. Ecological Applications, 19(3), 553-570.

Diaz, R. J., Solan, M., \& Valente, R. M. (2004). A review of approaches for classifying benthic habitats and evaluating habitat quality. Journal of Environmental Management, 73(3), 165-181.

Dramstad, W. E. (2009). Spatial metrics - useful indicators for society or mainly fun tools for landscape ecologists? Norsk Geografisk Tidsskrift-Norwegian Journal of Geography, 63(4), 246-254. doi:10.1080/00291950903368359.

ESRI. (2011). ArcGIS Desktop: Release 10. Redlands: Environmental Systems Research Institute.

Fang, S., Gertner, G., Wang, G., \& Anderson, A. (2006). The impact of misclassification in land use maps in the prediction of landscape dynamics. Landscape Ecology, 21(2), 233-242.

Fennessy, M. S., Jacobs, A. D., \& Kentula, M. E. (2004). Review of rapid methods for assessing wetland condition. (No. EPA/ 620/R-04/009). Washington, D.C.: U.S. Environmental Protection Agency.

Fennessy, M. S., Jacobs, A. D., \& Kentula, M. E. (2007). An evaluation of rapid methods for assessing the ecological condition of wetlands. Wetlands, 27(3), 543-560. 
Fisher, P. F. (1994). Visualization of the reliability in classified remotely sensed images. Photogrammetric Engineering and Remote Sensing, 60(7), 905-910.

Foody, G. M. (2002). Status of land cover classification accuracy assessment. Remote Sensing of Environment, 80(1), 185-201.

Fore, L. S., Karr, J. R., \& Conquest, L. L. (1994). Statistical properties of an index of biological integrity used to evaluate water-resources. Canadian Journal of Fisheries and Aquatic Sciences, 51(5), 1077-1087.

Fry, J. A., Xian, G., Jin, S., Dewitz, J. A., Homer, C. G., Limin, Y., et al. (2011). Completion of the 2006 national land cover database for the conterminous United States. Photogrammetric Engineering and Remote Sensing, 77(9), 858-864.

Goodchild, M. F. (2004). The validity and usefulness of laws in geographic information science and geography. Annals of the Association of American Geographers, 94(2), 300-303.

Google Earth. (2013). Flathead River System 48 30'00.39"N, $114^{\circ} 0^{\prime} 01.67^{\prime \prime} \mathrm{W}$, elevation $1000 \mathrm{M}$. Imagery Date $4 / 9 / 13$. Version 7.1.4. www.google.com/earth/. Accessed 1 June 2013.

Green, R., \& Chapman, P. M. (2011). The problem with indices. Marine Pollution Bulletin, 62(7), 1377-1380.

Gustafson, E. J. (1998). Quantifying landscape spatial pattern: what is the state of the art? Ecosystems, 1(2), 143-156.

Hauer, F. R., Cook, B. J., Gilbert, M. C., Clairain Jr, E. J., \& Smith, R. D. (2002). A regional guidebook for applying the hydrogeomorphic approach to assessing wetland functions of riverine floodplains in the northern Rocky Mountains. (No. ERDC/EL TR-02-21). Vicksburg, MS.: U.S. Army Engineer Research and Development Center.

Hawkins, C. P., Norris, R. H., Hogue, J. N., \& Feminella, J. W. (2000). Development and evaluation of predictive models for measuring the biological integrity of streams. Ecological Applications, 10(5), 1456-1477.

Hess, G. R., \& Bay, J. M. (1997). Generating confidence intervals for composition-based landscape indexes. Landscape Ecology, 12(5), 309-320.

Hierl, L. A., Franklin, J., Deutschman, D. H., Regan, H. M., \& Johnson, B. S. (2008). Assessing and prioritizing ecological communities for monitoring in a regional habitat conservation plan. Environmental Management, 42(1), 165-179.

Homer, C., Huang, C., Yang, L., Wylie, B., \& Coan, M. (2004). Development of a 2001 national land-cover database for the United States. Photogrammetric Engineering \& Remote Sensing, 70(7), 829-840.

Homer, C., Dewitz, J., Fry, J., Coan, M., Hossain, N., Larson, C., et al. (2007). Completion of the 2001 national land cover database for the conterminous United States. Photogrammetric Engineering and Remote Sensing, 73(4), 337.

Hyman, J. B., \& Leibowitz, S. G. (2000). A general framework for prioritizing land units for ecological protection and restoration. Environmental Management, 25(1), 2335.

Janssen, P. H., Petersen, A. C., van der Sluijs, J. P., Risbey, J. S., \& Ravetz, J. R. (2005). A guidance for assessing and communicating uncertainties. Water Science and Technology, 52(6), 125-134.

Jin, S., Yang, L., Danielson, P., Homer, C., Fry, J., \& Xian, G. (2013). A comprehensive change detection method for updating the national land cover database to circa 2011. Remote Sensing of Environment, 132, 159-175.

Joint Research Station. (2014). Guidos Toolbox. http://forest.jrc. ec.europa.eu/download/software/guidos/. Accessed 15 April 2014.

Klimas, C. V., Murray, E. O., Pagan, J., Langston, H., \& Foti, T. (2004). A regional guidebook for applying the hydrogeomorphic approach to assessing wetland functions of forested wetlands in the delta region of Arkansas Lower Mississippi River Alluvial Valley. (No. ERDC/EL TR-04-16). Vicksburg, MS: U.S. Army Engineer Research and Development Center.

Langford, W. T., Gergel, S. E., Dietterich, T. G., \& Cohen, W. (2006). Map misclassification can cause large errors in landscape pattern indices: examples from habitat fragmentation. Ecosystems, 9(3), 474-488.

Lausch, A., \& Herzog, F. (2002). Applicability of landscape metrics for the monitoring of landscape change: issues of scale, resolution and interpretability. Ecological Indicators, 2(1), 3-15.

Lovett, G. M., Burns, D. A., Driscoll, C. T., Jenkins, J. C., Mitchell, M. J., Rustad, L., et al. (2007). Who needs environmental monitoring? Frontiers in Ecology and the Environment, 5(5), 253-260.

May, R. M. (1985). Population biology: evolution of pesticide resistance. Nature, 315, 12-13.

Meixler, M. S., \& Bain, M. B. (2010). Landscape scale assessment of stream channel and riparian habitat restoration needs. Landscape and Ecological Engineering, 6(2), 235-245. doi:10.1007/s11355-010-0103-6.

Montana State Library (2011). Montana 2010 population density 1-km grid. GIS data. Helena, MT: Montana State Library.

Morley, S. A., \& Karr, J. R. (2002). Assessing and restoring the health of urban streams in the Puget Sound Basin. Conservation Biology, 16(6), 1498-1509.

MRLC, (Multi-Resolution Land Characteristics Consortium). (2013). National Land Cover Database. National Land Cover Database (NLCD). http://www.mrlc.gov/index.php. Accessed 1 Sept 2013.

Niemi, G. J., \& McDonald, M. E. (2004). Application of ecological indicators. Annual Review of Ecology, Evolution, and Systematics, 35, 89-111.

O’Neill, R. V., Riitters, K. H., Wickham, J. D., \& Jones, K. B. (1999). Landscape pattern metrics and regional assessment. Ecosystem Health, 5(4), 225-233.

Pennington, D. N., Hansel, J. R., \& Gorchov, D. L. (2010). Urbanization and riparian forest woody communities: diversity, composition, and structure within a metropolitan landscape. Biological Conservation, 143(1), 182194.

Pontius, R. G., Jr., \& Millones, M. (2011). Death to Kappa: birth of quantity disagreement and allocation disagreement for accuracy assessment. International Journal of Remote Sensing, 32(15), 4407-4429.

R Core Team. (2013). R: A Language and Environment for Statistical Computing. Vienna, Austria: R Foundation for Statistical Computing. http://www.R-project.org/.

Rains, M. C., Landry, S., Rains, K. C., Seidel, V., \& Crisman, T. L. (2013). Using net wetland loss, current wetland condition, and planned future watershed condition for wetland conservation planning and prioritization, Tampa Bay Watershed, Florida. Wetlands, 33(5), 949-963. 
Refsgaard, J. C., van der Sluijs, J. P., Hojberg, A. L., \& Vanrolleghem, P. A. (2007). Uncertainty in the environmental modelling process - a framework and guidance. Environmental Modelling \& Software, 22(11), 1543-1556. doi:10.1016/j.envost.2007.02.004.

Reiss, K. C., \& Brown, M. T. (2007). Evaluation of Florida palustrine wetlands: application of USEPA Levels 1, 2, and 3 assessment methods. EcoHealth, 4(2), 206-218. doi:10. 1007/s10393-007-0107-3.

Seegert, G. (2000). The development, use, and misuse of biocriteria with an emphasis on the index of biotic integrity. Environmental Science \& Policy, 3, 51-58.

Shao, G., \& Wu, J. (2008). On the accuracy of landscape pattern analysis using remote sensing data. Landscape Ecology, 23(5), 505-511.

Shao, G., Liu, D., \& Zhao, G. (2001). Relationships of image classification accuracy and variation of landscape statistics. Canadian Journal of Remote Sensing, 27(1), 33-43.

Smith, R. D., Ammann, A., Bartoldus, C., \& Brinson, M. M. (1995). Approach for assessing wetland functions using hydrogeomorphic classification, reference wetlands, and functional indices. (No. WRP-DE-9). Vicksburg, MS.: U.S. Army Engineer Waterways Experiment Station.

Soille, P., \& Vogt, P. (2009). Morphological segmentation of binary patterns. Pattern Recognition Letters, 30(4), 456-459.

Steel, E. A., Feist, B. E., Jensen, D. W., Pess, G. R., Sheer, M. B., Brauner, J. B., \& Bilby, R. E. (2004). Landscape models to understand steelhead (Oncorhynchus mykiss) distribution and help prioritize barrier removals in the Willamette basin, Oregon, USA. Canadian Journal of Fisheries and Aquatic Sciences, 61(6), 999-1011.

Stehman, S. V. (1997). Selecting and interpreting measures of thematic classification accuracy. Remote Sensing of Environment, 62(1), 77-89.

Stein, E. D., Fetscher, A. E., Clark, R. P., Wiskind, A., Grenier, J. L., Sutula, M., et al. (2009). Validation of a wetland rapid assessment method: use of EPA's level 1-2-3 framework for method testing and refinement. Wetlands, 29(2), 648-665.

Stoddard, J. L., Herlihy, A. T., Peck, D. V., Hughes, R. M., Whittier, T. R., \& Tarquinio, E. (2008). A process for creating multimetric indices for large-scale aquatic surveys. Journal of the North American Benthological Society, 27(4), 878891.

Suarez-Rubio, M., Lookingbill, T. R., \& Elmore, A. J. (2012). Exurban development derived from Landsat from 1986 to 2009 surrounding the District of Columbia, USA. Remote Sensing of Environment, 124, 360-370.

Tiner, R. W. (2004). Remotely-sensed indicators for monitoring the general condition of "natural habitat" in watersheds: an application for Delaware's Nanticoke River watershed. Ecological Indicators, 4(4), 227-243.

Tobler, W. R. (1970). A computer movie simulating urban growth in the Detroit region. Economic Geography, 46, 234-240.
Turnhout, E., Hisschemöller, M., \& Eijsackers, H. (2007). Ecological indicators: between the two fires of science and policy. Ecological Indicators, 7(2), 215-228.

Uricchio, V. F., Giordano, R., \& Lopez, N. (2004). A fuzzy knowledge-based decision support system for groundwater pollution risk evaluation. Journal of Environmental Management, 73(3), 189-197. doi:10.1016/j.jenvman.2004.06.011.

USEPA, (U.S. Environmental Protection Agency). (2012). The economic benefits of protecting healthy watersheds. http:// water.epa.gov/polwaste/nps/watershed/upload/economic benefits_factsheet3.pdf. Accessed 15 April 2014.

USEPA, (U.S. Environmental Protection Agency). (2013). National wetland condition assessment. http://water.epa. gov/type/wetlands/assessment/survey/. Accessed 1 September 2013.

USGS, (U.S. Geological Survey). (2013). Digital Elevation Map: Seamless Data. http://nationalmap.gov/viewer.html. Accessed 1 Oct 2013.

USGS, (U.S. Geological Survey). (2014). The National Map Viewer. The National Map Viewer and Download Platform. http://nationalmap.gov/viewer.html. Accessed 21 April 2014.

Vogelmann, J. E., Howard, S. M., Yang, L., Larson, C. R., Wylie, B. K., \& van Driel, N. (2001). Completion of the 1990s National Land Cover Data set for the conterminous United States from Landsat Thematic Mapper data and ancillary data sources. Photogrammetric Engineering and Remote Sensing, 67(6), 650-662.

Vogt, P., Riitters, K. H., Estreguil, C., Kozak, J., Wade, T. G., \& Wickham, J. D. (2007). Mapping spatial patterns with morphological image processing. Landscape Ecology, 22(2), 171-177.

Walker, W. E., Harremoës, P., Rotmans, J., van der Sluijs, J. P., van Asselt, M. B., Janssen, P., \& Krayer von Krauss, M. P. (2003). Defining uncertainty: a conceptual basis for uncertainty management in model-based decision support. Integrated Assessment, 4(1), 5-17.

Weller, D. E., Snyder, M. N., Whigham, D. F., Jacobs, A. D., \& Jordan, T. E. (2007). Landscape indicators of wetland condition in the Nanticoke River watershed, Maryland and Delaware, USA. Wetlands, 27(3), 498-514.

Whigham, D. E., Lee, L. C., Brinson, M. M., Rheinhardt, R. D., Rains, M. C., Mason, J. A., et al. (1999). Hydrogeomorphic (HGM) assessment - a test of user consistency. Wetlands, 19(3), 560-569.

Wickham, J. D., O’neill, R. V., Riitters, K. H., Wade, T. G., Jones, K. B., \& others. (1997). Sensitivity of selected landscape pattern metrics to land-cover misclassification and differences in land-cover composition. Photogrammetric Engineering and Remote Sensing, 63(4), 397-401.

Wickham, J. D., Stehman, S. V., Gass, L., Dewitz, J., Fry, J. A., \& Wade, T. G. (2013). Accuracy assessment of NLCD 2006 land cover and impervious surface. Remote Sensing of Environment, 130, 294-304. 